Vol. 8, Issue 12, December 2021

DOI: $10.17148 /$ IARJSET.2021.81233

\title{
FLAVONOIDS: The NATURE'S GIFT to MANKIND
}

\author{
Mridula Verma \\ Associate Professor, Department of Chemistry, M.M.H College, Ghaziabad, India
}

\begin{abstract}
The Flavonoids naturally occurring plant pigments, natural polyphenols are secondary metabolites and are interesting class of phytochemicals due to their pharmacological properties. The potency of different class of flavonoids in medicinal uses are attributed to their chemical structures. The basic structure is a Diphenyl propane skeleton in which two benzene rings are linked by a chain of three carbon which forms a closed pyran ring. The substitution pattern and nature of substituents decide the potency of flavonoids against a particular disease and make them an interesting class of phytochemicals.
\end{abstract}

Keywords: Flavonoids, Polyphenols, Flavone, Antioxidants, Radical Scavenging

\section{INTRODUCTION}

Flavonoids are a large collection of naturally occurring plant pigments. The medical applications of these naturally occurring substances have always been a field of interests for phytochemists. These naturally abundant plant pigments are phenolic and polyphenolic in nature and have various remarkable pharmaceutical values. Flavonoids or bioflavonoids are also known as Vitamin $\mathrm{P}$ and citrin. The medicinal value of natural products always draw attention of phytochemists and is a field to explore. Flavonoids in particular among various natural substances are abundant in nature, good sources form plant origin. The bioavailability and bioactivity of flavonoids make them an important class of natural pigments. Flavones are the highest explored subclass of flavonoids and are present in nature both as $\mathrm{O}-$ and C- glycosides and are easily absorbed by intestine. Basic skeleton structure of all flavonoids has Benzopyrane ring (1). All flavonoids are polyphenols but polyphenols are not flavonoids/flavones. . The flavonoids are secondary metabolites of plants and fungus and provide color to flowers, fruits and some leaves. The coloring pattern is based on the chemical structures of chromophoric moieties and provide some properties like UV filtration, nitrogen fixation, floral pigmentations etc. The various types of natural flavonoids are Flavones, Anthocyanidines, Flavonones, Isoflavones, Flavonols, Quercetin, Catechin, Anthocyanin, Luteolin, Myrcicetin, Naringenin etc.

All flavonoids are natural occurring in origin whereas, polyphenols may be natural, synthetic or semi synthetic. Flavonoids are free radical scavengers and helpful in controlling Dementia as these reduce oxidative stress the main cause of Dementia [1]. By enhancing effective cellular activity in positive direction flavonoids regulate the body metabolism. The polyphenolic nature of flavonoid make them powerful antioxidant. Thus these are pharmacologically important against coronary heart diseases, potential viral activities, cancer cells growth and liver functions [2]. Flavonoids as flavones also have neuroprotective and anti-inflammatory properties. The cost effective and abundant natural sources make them a field of interest for phytochemiststs. Commercially these are also used in skincare products [3,4]. The health promoting properties of flavonoids due to their high antioxidant capacity have been studied both in vivo and in vitro systems $[5,6]$.

\section{BIOACTIVITY of FLAVONES and STRUCTURAL CORRELATION}

The wide range of flavonoids present in nature and their bioactivities cover against a broad range of diseases, behaving like anti-viral, anti-inflammatory, cardio protective, anticancer, anti-dementia, anti-oxidative stress, anti-aging etc. The structural correlation with the potency of bioactivity has been reported [7]. The various epidemiological studies have suggested that flavonoids in general have a remarkable impact on suppressing the development of various diseases and it has been suggested that the typical structure of flavonoids help to interact it with enzyme systems of crucial metabolic pathways to help them act positively[8]. The close relationship between the benzopyran/benzopyrone skeleton of flavonoids with various substituents and their pharmacological effects have been studied and found to be an important factor [9]. The $\mathrm{C}_{2}=\mathrm{C}_{3}$ double bond in parent skeleton has been documented in most cases as a basic favorable moiety in the bioactivities of flavonoids as phytochemicals [10]. The flavone with 5-/7- hydroxyl groups and their derivatives have shown a positive impact against $\mathrm{H}_{5} \mathrm{~N}_{1}$ influenza virus. The lower hydrophobicity due to increasing no. of hydroxyl groups has been attributed to obstructive for the flavonoids to partition into biological membranes with 


\title{
International Advanced Research Journal in Science, Engineering and Technology
}

\author{
Vol. 8, Issue 12, December 2021
}

\section{DOI: $10.17148 /$ IARJSET.2021.81233}

some exceptions[11]. A study on nine flavonoids isolated from the leaves of Zanthoxylum bungeanum and their antioxidant activity suggested that the flavonoids having - $\mathrm{OH}$ group at 4' position of $\mathrm{B}$ ring and 7-position of A ring show highest antioxidant activity[12]. The medicinal activity of flavonoids depends on their chemical structure, degree of unsaturation, and number and position of hydroxyl groups. Tian yang.Wang et al. have reported an extensive study on the relationship between structures of polyphenolic flavones and their medicinal potentiality [13]. According to them the basic structure consisting of $\mathrm{C}_{6}-\mathrm{C}_{3}-\mathrm{C}_{6}$ rings with different substitution patterns are the precursors of several series of subclass compounds and formulated graphically Fig.1. The antioxidant and prooxidant potentiality of flavonoids have been attributed to their ionization during radical scavenging mechanism of free radicals Fig.2 [14]. A broad spectrum of study of correlation between chemical structures and antioxidant, prooxidant and anti trypanosomatid properties suggested that hydroxy substituents in the basic skeleton play the key role [15]. The various pharmacological activities of flavoneshave been attributed to the number of hydroxyl groups attached to the basic structures of these compounds. Since most of the flavones occur in glycosidic forms and the absorption is comparatively smoother in gastrointestinal tract their medicinal importance is continuously increasing [16].

\section{CLASSIFICATIONS}

The flavonoids can be divided into various classes based on the oxidation level of the ring C like flavones, Flava-3-ols, flavonols, Anthocyanins, Dihydroflavanols , Isoflavones and flavonones.

\section{A. FLAVONES}

Flavones (2) main structure includes an olefinic linkage between $\mathrm{C}_{2}$ and $\mathrm{C}_{3}$ of basic skeleton and pyrone ring i.e. a carbonyl at position $\mathrm{C}_{4}$ in the central ring. Such types of flavones are pale yellow in color and are abundant in derivative forms such as Luteolin, Woganin, Apigenin, Balcalein etc.

\section{B. FLAVONOLS}

Flavonols (3) also has an olefinic linkage between $\mathrm{C}_{2} \& \mathrm{C}_{3}$, This class of flavonoids also have at least one -OH group at $\mathrm{C}_{3}$ of basic skeleton e.g. Quercetin, Kaempferol, Myricetin, Fiscetin etc. These are commonly found in onions, kale, lettuces, tomatoes, apples, grapes and berries.

\section{C.FLAVANONES}

Flavanones(4) basic skeleton is similar to flavones and these are precursors to many important biological processes. The central ring is saturated and these are also called dihydroflavones [17].

D. FLAVAN-3-OLS

Flavan-3ols(5) possess one hydroxyl grout at $\mathrm{C}_{3}$ position of central ring and do not have carbonyl system as part of the ring. Colorless in appearance e.g. Gallate, epicatechin,catechins, gallowcatechines etc. The $\mathrm{C}_{2}$ and $\mathrm{C}_{3}$ carbons are asymmetric and give four isomers for each flavan-3-ol molecule. These are common in grapes and berries.

\section{E. ANTHOCYANIDINS}

Anthocyanidins (6) has One hydroxy group at $\mathrm{C}_{3}$ and a double bond between $\mathrm{C}_{3} \& \mathrm{C}_{4}$ of central ring, water soluble and provide red to purple colour in plants. These are sugar free counterparts of anthocyanins. These are based on the flavylium cation, an oxonium ion with various substituents. These are also known as universal colorants and are a class with highest percentage of bioflavonoids.

\section{F. ISOFLAVONES}

Isoflavones(7) basic structure is 3-phenylchromen skeleton. Sometimes extra heterocyclic ring as D ring is present e.g. rotenoid, coumestane, genisteine, daidzein etc.[18]. Isoflavones occur in four related structures named aglycons, 7-Oglucosides, 6'-O-acetylglucosides and 7-O-malonylglucosides. These are closely related to phytoestrogens and are sold as dietary supplements.

\section{STRUCTURAL ANALYSIS and POTENCY as PHYTOCHEMICALS}

Despite the widely substantiated bioactivity of flavonoids the in vivo mechanism is still a little uncertain. The best described property of all the types of flavonoids is their antioxidant activity via radical scavenging which has been mostly studied in vitro[19]. The antioxidant capacity of flavonoids has been associated to their ability to act as effective scavengers of most types of oxidizing species such as RONS through mechanisms that involve the transfer of $\mathrm{H}$ atom 


\section{DOI: 10.17148/IARJSET.2021.81233}

(HAT) or of a single electron (SET) to the radical to stabilize. The metal chelating efficiency has also been studied for the radical scavenging tendency in vitro[20]. The toxicity of the metal ions has been attributed their catalyzing capacity of oxidant species leading to the oxidation at different cellularl evels(Lipids, DNA, proteins). The metal ions catalyze the formation of $\bullet \mathrm{OH}$ or $\bullet \mathrm{O}_{2}$ radicals. The flavonoids having various hydroxyl groups at various positions of the basic skeleton and carbonyl group effectively react with metal ions forming complexes and suppress the radical generation $[21,22]$. The inverse relationship between dietary intake of citrus fruits and cardiovascular diseases has been studied both in vitro and in vivo and importance of polyhydroxy substitution has been reported [23]. Flavonoids also inhibit the enzymes involved in ROS generation i.e. microsomal monooxygenase, glutathione-S-transferase, mitochondrial succinoxidase, NADH oxidase etc. Lipid peroxidation is a common consequence of oxidative stress. Due to their lower redox potentials flavonoids are thermodynamically able to reduce highly oxidizing free radicals (redox potentials in the range 2.13-1.0V) such as super oxide, peroxide, peroxyl, alkoxyl and hydroxyl radicals by H-atom donation [24]. The free radical scavenging efficiency, antioxidant and metal chelation properties of flavonoids have been unanimously attributedto the presence - $\mathrm{OH}$ group at $\mathrm{C}_{3}$, an olefinic linkage between $\mathrm{C}_{2}$ and $\mathrm{C}_{3}$ and a carbonyl at $\mathrm{C}_{4}$ positions [25]. The polyhydroxyletion of rings $\mathrm{A}$ and $\mathrm{B}$ enhance the potency of concerned flavonoid. Flavonoids are absorbed from the gastrointestinal tract of humans and animals and are excreted either unchanged or as flavonoid metabolites in the urine and feces. Epidemiological studies show an inverse correlation between dietary flavonoid intake and mortality rate from coronary heart disease (CHD) which is explained in part by the inhibition of low density lipoprotein (LDL) oxidation and reduced platelet agreeability. The potential antioxidant activity of citrus flavonoids showed significant impact on blood and microvascular endothelial cells. Many of the pharmacological properties of citrus flavonoids can be linked to the abilities of these compounds to inhibit enzymes involved in cell activation [26]. An interesting study over a broad range of biological activities of E.Coli and reactivity mechanism of polyphenolic substances (flavonoids, methoxy flavonoids, isoflavonoids etc.) showed that some polyphenols rigidified the ribosomal membrane whereas some decreased membrane fluidity[27]. The polypharmacological behaviour of flavonoids are attributed to their chemical structures. The patterns of methoxylation, glycosylation and hydroxylation decide their potency against influenza virus, canine distemper virus, hepatitis $C$ virus and E.Coli $[28,29,30,31]$. The antiviral activity appeared to be associated with the non glycosidic compounds as well as hydroxylation at $\mathrm{C}_{3}$. The antiulcerogenic properties are the result of inhibition of related metabolites in presence of certain flavanoids. The $C_{2}=C_{3}$ linkage provides planarity to the system and extended conjugation between rings $\mathrm{C}$ and $\mathrm{A} / \mathrm{B}$ provide much needed environment for anti tumor activity. The coexistence of $\mathrm{C}=\mathrm{C}$ linkage and two hydroxyl groups in ring $\mathrm{B}$ works against the development of cancer cells [32]. The results of reactions of flavonoids with paraoxonase-1 (re PON 1) have shown that $\mathrm{C}_{2}=\mathrm{C}_{3}$ in ring $\mathrm{C}_{-}$along with a carbonyl at $\mathrm{C}_{4}$ have remarkable effects against cancer cells and make flavonoids as potent anti cancer phytochemicals $[33,34,35]$.

\section{CONCLUSION}

Dietary flavonoids are important class of naturally occurring phytochemicals acting as secondary metabolites. The polyphenolic substitution on the basic skeleton along with their derivatives help them to act as powerful antioxidants, active substances against many diseases both in vitro and in vivo. The natural abundacy, structural peculiarity and a close correlation between their chemical structures and potential as phytochemicals make them an interesting field of endless exploration. They act through cell signaling pathways and possess remarkable efficiency as antioxidants .

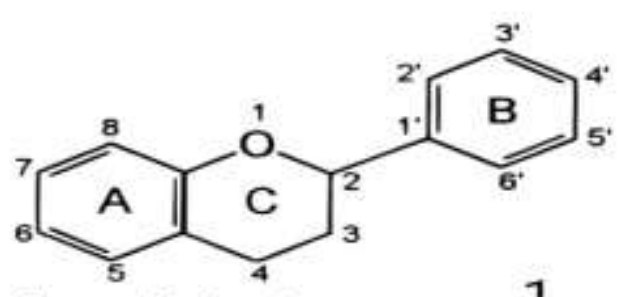

Basic flavonoid structure.

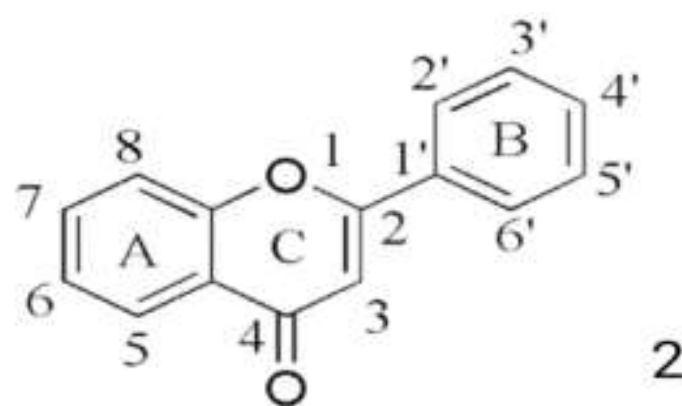


<smiles>O=c1oc2ccccc2s1</smiles>

3<smiles>O=C1C[C@H](c2ccccc2)Oc2ccccc21</smiles><smiles>OC1Cc2ccccc2OC1c1ccccc1</smiles>

5<smiles>COc1cc(-c2cc(O)c(O)c(O)c2C=C(C)O)cc(C=O)c1O</smiles>

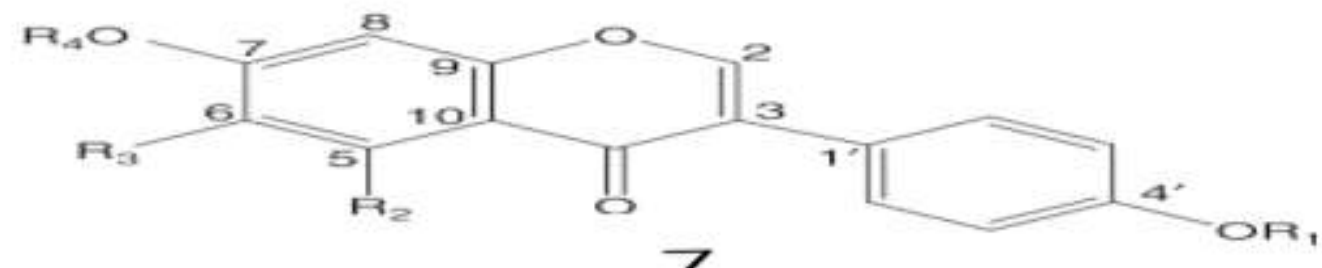

$\mathrm{OH}$

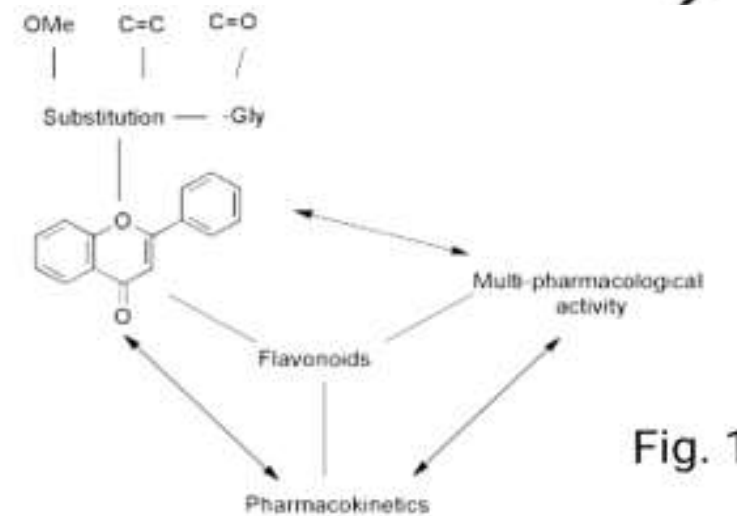

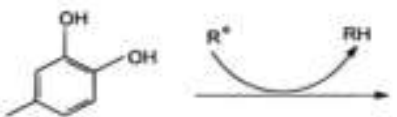

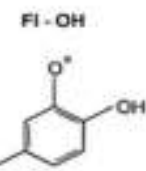

Fig. 1

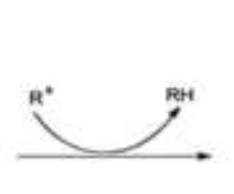

Fig. 2

\section{REFERENCES}

[1]. Kumiko Ishige, David Schubert and Yutaka Sagara, Free Radical Biology and Medicine, 30 (4), 433-446, 2001

[2]. Hower D.Sesso,J. Michael Gaziano, Simin Liu, Julie E. Buring, The American Journal of Clinical Nutrition, 77(6), 1400-1408, 2003

[3]. G.Lanzendorfer, F. Stab, S.UntiedtCosmetic and Dermatological Preparations withflavonoids, 1996

[4]. M. Danihelova, J. Viskupicova, Sturdik, Lipophilization of flavonoids for their food, therapeutic and cosmetic applications.Actachim. Slovaca, 5, 59-69, 2012

[5]. N.C.Cook and Samman, Journal of Nutritional Biochemistry, 7, No. 2, 66-76, 1996

[6]. C.A.Rice - Evans, N. J. Miller, P. G. Bulwell,P.M. Bromlayand J.B. Pridhem, Free Radical Research, 22, No.4, 375-383, 1995

[7]. Muhammed Ajaib, Pharmacology, online1, 135-143,2013

[8]. J. Krych, L. Gebicka, Int. J. BiolMacromol.,58, 148-153,2013

[9]. C Rakers, S.M.Schwerdtfeger, J. Mortier et al., Bioorg. Med. Chem. Lett, 24(17), 4312-4317,2014

[10]. T. T. Nguyen, Y. H. Moon, Y.B. Ryu et al., Enzyme MicrobTechnol, 52(1), 26-31,2013

[11]. Wu T., He M., Zang X. et al.,BiochimBiophysActa, 1828(11), 2751-2756,2013

[12]. Yujuan Zhang, DonǵmeiWang, Lina Yang, Dan Zhou, Jingfang Zhang Plo S one 9(8), e105725, 2014

[13]. Tian-yang Wang, Qing Li, Kai-shun Bi, Asian Journal of Pharmaceutical Sciences, 13, 12-23, 2018

[14]. Z. Markovic, D. Milenkovick, J.Dorovic et al., Food Chemistry, 135(3), 2070- 2077, 2012

[15]. Joao Luiz Baldim, BinacaGoncalves, Vasconcelos de Alcantara, Olivia do SilvaDomingos, Marisi Gomes Soares, Ivo SantanaCaldas, RomulDias Novas, Tiago BranquinhoOleveira, Joao Henrique Ghilardi Lago, Daniela Aparacida Chagas-Paula , Oxidative 
International Advanced Research Journal in Science, Engineering and Technology

Vol. 8, Issue 12, December 2021

DOI: $10.17148 /$ IARJSET.2021.81233

Medicine andHCellular Longevity, 2017, 2017

[16]. C. A. Rice- Evans, N. Miller and G. Paganga, Free Radical Biology and Medicine, 20(7), 933-956, 1996

[17]. F. R. Marin, M. J. Fruits, J. A. Perez-Alvarez, F. Martinez sanchez, J. A. Del Rio, Studies in Natural Products Chemistry, 26,741- 778, 2002

[18]. J..P. Marais, B. Devours, R.A. Dixon and D.Ferriera, Stereochemistry of Flavonoids, 3, 2006

[19]. K. F. Heim, A. R. Tagliaferro and D. J.Bobilya, J. Nutr. Biochemistry., 13, 572- 584,2002

[20]. J, Treml, K. Smejkal. Compr. Rev. Food Se., Food saf. ,720-738,2016

[21].S.A. Cherrak, N. Mokhatri- Soulimane, F. Berroukeche. B. Bensename, A. Cherbonnel, H. Merzouk, M. Elhabiri,PLoS ONE, 11(10), : e0165575, 2016

[22]. M. Leopoldini, N. Russo, M. Toscano, Food Chem., 125, 288-306, 2011

[23]. E. Tripoli, M. La Guardia, S.Giammanco, D.DiMajo, M. Giammanco (E. Tripoli et al), Food Chemistry, 104,466-479,2007

[24]. Shashank Kumar, Abay k. Pandey The scientific World Journal, (2013), 2013

[25]. Pier- Giorgio Pietta, J. Nat. Prod., 63, 1035- 1042, 2000

[26]. O Benavente-Garcia, J. Castillo. Journal of Agricultural and Food Chemistry, 56 (15), 6185- 6205, 2008

[27]. Ting Wu, Mengying He, XixiZang, Ying Zhou, TianfuQiu, Siyi Pan, Xiaoyun Xu. Biochimica et BiophysicaActa (BBA) -

Biomembranes, 1828(11), 1751 -2756, 2013

[28]. C. Shibata, M. Ohno, M. Otsuka et al. , Virology, 42- 48, 462-463, 2014

[29]. T T.Nguyen, Y VirologyY B Ryu et al., Enzyme Microb. Technol. 52 (1), 26-31, 2013

[30]. D Atrahimovich, J Vaya, S. Khatib, Bioorg. Med Chem., 21(11), 3348-3355, 2013

[31]. O V Carvalho, C V Botelho, C. G. Ferreira et al., Res. Vet. Sci, 95, (2),717-724 .2013

[32]. Z.Huang, F. Fang, J. Wang et al., FEBS Lett., 584(1), 22 -26, 2014

[33]. S. Bose, D. Sarkar, A. Bose and S. C. Mandalay, The Pharma Review, July-Aug. , 2018

[34]. G. Kothandan, C G Gadhe, T. Madhavan et al., Eur. J. Med. Chem., 46( 9), 4078- 4088, 2011

[35]. R. E. Mutha, A. U. Tatia and S. J. Surana, Futur J. Pharm Sci, 7, 25, 2021 